\title{
HABLAR MEJOR DE LO MISMO
}

CARlos PEREDA

INSTITUTO DE INVESTIGACIONES FILOSÓFICAS

UNIVERSIDAD Nacional AUTÓNOMa de MÉXICO

Una argumentación comienza a partir del planteo de un problema y se desarrolla con la introducción de propuestas para solucionarlo y sucesivas defensas y ataques con respecto a esas propuestas. Así, en un ciclo argumental encontramos tres papeles básicos, un proponente, un oponente y un juez: tres papeles que con frecuencia asume una misma persona argumentando consigo misma. El proponente tiene la tarea de defender con razones sus propuestas, y el oponente, de atacarlas también con razones; a su vez, el juez decide quién tiene razón; cuando por faltas de comprensión estas obligaciones no se pueden cumplir, un ciclo argumental no se configura, no se pone en marcha. Sin embargo, a veces los ciclos argumentales, aunque ya se encuentran en funcionamiento, se bloquean al toparse sus participantes con nuevas faltas de comprensión; en cualquiera de esos casos, para poder reanudar los debates, se tiene que recurrir a un papel auxiliar de los anteriores: el papel del intérprete y sus funciones, su "trama del interpretar", trama que a la que suele aludirse con palabras como "aclarar", "analizar", "elucidar", "reconstruir"... (¿y hasta "deconstruir"?), operaciones que es posible agrupar en un ciclo auxiliar de los otros ciclos argumentales, que podemos denominar "ciclo reconstructivo"."

La pretensión, por lo pronto, la pretensión ingenua de toda la trama del interpretar, o al menos, de muchas de las operaciones de cualquier ciclo reconstructivo, consiste en: "hablar mejor de lo mismo" que ya se ha hablado, pero no en el sentido de la pompa retórica, de la vanidad palabrera, sino hablando de modo tal que el intérprete pueda eliminar las faltas de comprensión que interrumpen la comunicación, que bloquean los argumentos. Se quiere pensar, pues, a la expresión "hablar mejor de lo mismo" no como una consigna retórica, sino, en alguna medida, como una consigna antirretórica. Un ejemplo muy elemental: si en medio de un debate encuentro la palabra "conmoción" y no la entiendo o la entiendo a medias, la función del

1 Para mayor información acerca de este modelo de argumentación, véase C. Pereda, Vértigos argumentales. Una ética de la disputa, Editorial Anthropos, Barcelona, 1994. 
intérprete consiste en aclarar, analizar, elucidar, reconstruir..., como lo hace un diccionario, el sentido que posee esta palabra en la lengua castellana (digamos, indicar que con la palabra "conmoción" se alude al movimiento - perturbación violenta del ánimo o del cuerpo, o a un tumulto que altera la vida de un Estado o pueblo, o a un movimiento sísmico muy perceptible), y/o señalar cómo se usa específicamente esa palabra en el habla en cuestión, y hasta, tal vez, cómo se la debería usar. Atender las tareas del papel de "intérprete" conduce, entonces, a pensar el problema acerca de qué significa "hablar mejor de lo mismo", a preguntarse: ¿qué estamos haciendo, en realidad, cuando aclaramos, analizamos, elucidamos, reconstruimos las palabras de los otros o nuestras propias palabras?

Sin embargo, lo que califiqué como "pretensión ingenua" del ciclo reconstructivo ¿es legítimo? Que es otra manera de preguntarse: ¿es posible "hablar mejor de lo mismo"? Quizá tal pregunta, a primera vista al menos, resulte extravagante. No obstante, apenas se la examina con cuidado, deja de serlo; más todavía, se convierte en una inquietante sospecha que siembra la reflexión de crecientes dificultades acerca de las tareas del intérprete. ¿Cómo es esto?

Ante todo, comienzo por explorar un viejo y conocido territorio y, además, de manera muy elemental: enumeraré algunas de esas operaciones del intérprete, varios de los procedimientos que buscan poner en claro lo que ya se ha dicho, reservando para todos ellos la palabra "reconstrucción", o si se prefiere, "reconstrucción racional"; cuidado, sin embargo: aquello que me preocupa no es ningún extraño procedimiento teórico, sino un conjunto de operaciones comunes, presentes todo el tiempo en nuestra comunicación (I). Después de recordar - un poco aburridamente- el campo ejemplar de conceptos como reconstrucción, o análisis, busco indagar en qué consisten realmente esas operaciones, examinando varias consignas que se han propuesto acerca del concepto de análisis (II). Luego paso a discutir una conjetura: en la teoría de la referencia directa y en el concepto de política conceptual, acaso podríamos encontrar vías para solucionar, o más bien, disolver cierta versión de la tradicional "paradoja del análisis", paradoja que parece eliminar la posibilidad misma de "hablar mejor de lo mismo" (III). Dos dudas todavía me inquietan hacia el final de la discusión (IV).

\section{Recordatorio de algunas técnicas de reconstrucción}

Se conoce que, a veces, quien argumenta, si se deja llevar por las palabras que inmediatamente percibe, por la forma superficial de un enunciado, se enreda en laberintos; en estas situaciones lo que se necesita es dejar de usar los enunciados en cuestión y atenderlos un poco como intérprete, rescatando su forma real, la forma lógica agazapada detrás de la forma gramatical. 
Estas técnicas de reconstrucción suelen llamarse "reconstrucciones formales". Las caracterizo como sigue:

Para llevar a cabo una reconstrucción formal del enunciado $E$ se tiene que:

a) dejar de usar $E$;

b) ofrecer la forma genuina de $E$, de tal manera que ésta nos entregue con más claridad (i) lo que se quería decir más confusamente con $\mathrm{E}$ o (ii) lo que se debería querer decir con $E$.

Atendamos la siguiente oración:

(1) Segismundo nos dará trabajo pronto.

El sentido de (1) depende de las circunstancias en que se profiera (1). Supongamos una situación en la que un intérprete se las atribuye a un actor, quien se las dice a sus compañeros refiriéndose al personaje de Calderón en la obra de teatro La vida es sueño; desde ese momento sabemos que Segismundo es el nombre de una ficción. A su vez, "dar trabajo" es una acción que debe ser realizada por uno o varios agentes; un personaje de ficción no es un agente de la misma manera en que pueden serlo los dueños o los empleados de una panadería. Una reconstrucción formal de (1), mediante una paráfrasis en el mismo lenguaje, podría ser:

(2) El hecho de que pronto se ponga en escena la obra de Calderón La vida es sueño constituirá una buena oportunidad de trabajo para todos los actores que intervengan en ella.

Podemos afirmar ya, entonces, que (2) "habla mejor de lo mismo" que (1). Otro ejemplo, tal vez con mayores ramificaciones:

(3) El saber no ofende ni teme.

¿Le atribuimos a un agente en (3) las acciones de no ofender y no temer? La oración (3) posee la misma forma gramatical que:

Los empleados de la panadería "Progreso" no ofenden ni temen.

Sin embargo, el saber no es un agente en el sentido en que lo son los empleados de una panadería. ¿Se trata acaso de un "agente universal"?, ¿tal vez de un "agente abstracto"? Sin embargo, ¿dónde se encuentra esa clase de agentes? Y si no se encontraran en ninguna parte, ¿qué sentido tendría hablar de agentes que no se encuentran en ninguna parte?

Cualquier intérprete dispone de distintos grados de formalización (como se dice: "diferentes posibilidades de quitarle la paja a un argumento"). No obstante, el modelo de cualquier formalización, formalizar en sentido estricto, se obtiene en un lenguaje canónico. Si se representa "ofender", 
"temer" y "saber" con sus iniciales, una propuesta de reconstrucción formal en sentido estricto de (3) podría ser la siguiente:

(4) $\sim O(s) \sim T(s)$.

(4) configura una propuesta de reconstrucción radicalmente platónica: cuantifica sobre universales. $O$ tal vez, como sospecho, nos encontramos ante una incomprensión acerca del para qué de una reconstrucción formal llevada a cabo con simbolismo lógico. En (4), el simbolismo funciona como notación taquigráfica (la nueva notación no agrega ni quita teóricamente nada a lo que ya se decía con palabras); sin embargo, la lógica no es una rama de la taquigrafía, sino una clase de teoría. Formalizar un enunciado no consiste en escribir ese enunciado con otros signos, sino en ofrecer una interpretación de su estructura. Una reconstrucción formal más defendible de (3) podría ser:

(5) $(x)(S(x) \supset \sim O(x) \wedge \sim T(x))$.

En (4) se presupone la existencia de agentes universales o de agentes abstractos, mientras que (5) los elimina: la diferencia no es de signos sino de estructura, por eso, la reconstrucción formal puede señalar qué se está en realidad afirmando, a qué nos comprometemos ontológicamente cuando decimos lo que decimos. De esta manera, esta técnica evita, entre otras tentaciones, la de multiplicar realidades de modo arbitrario, convirtiendo las ficciones o los atributos como "saber" en agentes de acciones.

El contraste entre las dos versiones presentadas de reconstrucción formal, la reconstrucción formal como paráfrasis en el lenguaje ordinario o como formalización en sentido estricto (en lenguaje canónico), desempeñó un papel importante en muchas discusiones. Me detengo un momento a recordar, a llevar a cabo un poco de historia. En La lógica sintáctica del lenguaje, ${ }^{2}$ Carnap defiende reconstrucciones formales de la clase a la que pertenece (5), por ejemplo. En el capítulo $\mathrm{V}$ de dicho libro leemos que las preguntas que hay que tratar en cualquier campo teórico pueden agruparse en "preguntas de objeto" y "preguntas lógicas"; las preguntas de objeto son aquellas que tienen que ver con los objetos del dominio que se considera, digamos, las preguntas del químico acerca de las propiedades del potasio; en cambio, las preguntas lógicas se refieren a las oraciones, los términos y las teorías, y sólo éstas, a su vez, se refieren a los objetos, a la manera de reconstrucciones como: "icómo usas tú la palabra 'potasio"?" Cuando se habla sobre un dominio específico de objetos, como es el caso de cualquier argumentación en las ciencias naturales, la distinción entre ambas clases de preguntas es clara; por el contrario, apenas se abandonan estos dominios, se suelen confundir estas preguntas y así nos sumimos en los peores enre-

2 Logische Syntax der Sprache, Viena, 1934. 
dos. Carnap propone la siguiente terapia: en relación con las preguntas de objeto cuyos objetos no ocurren en las ciencias, es necesario eliminarlas en tanto pseudoproblemas; por ejemplo, las supuestas oraciones de la metafísica, oraciones sobre pseudobjetos como la cosa en sí, el no ser, el absoluto, la causa primera..., u oraciones de la filosofía de la historia a la manera de preguntas como "ia dónde va la historia?", son oraciones sin contenido, oraciones "meramente retóricas", sólo expresan sentimientos, los que, a su vez, estimulan los sentimientos y las tendencias volitivas de los oyentes. De ahí que, para Carnap, cualesquiera preguntas de objeto que ocurran, por ejemplo, en un problema no empírico genuino (preguntas acerca de qué son los números, la causalidad, el tiempo, el espacio...), son, en primer lugar, preguntas cuya formulación enrevesada las hace aparecer como si se estuviesen refiriendo a objetos pero, en realidad, se refieren a oraciones, términos y teorías y son, por lo tanto, preguntas lógicas. En segundo lugar, todas las preguntas lógicas son capaces de presentarse como preguntas sintácticas y de recibir una formalización en sentido estricto, siendo las preguntas de pseudobjeto simplemente preguntas cuasisintácticas. Esta distinción se aclara con el contraste entre "modo formal" y "modo material" de hablar que presenta el capítulo IV de La lógica sintáctica..., en su parágrafo 64: pertenece al modo material de hablar cualquier enunciado que atribuya a un objeto una propiedad cuasisintáctica, en contraste con el modo material de hablar, en el que tratamos con enunciados sintácticos. ${ }^{3}$ Usando estas distinciones, Carnap propone la siguiente clasificación de oraciones: ${ }^{4}$

a) oraciones de objeto: "Babilonia fue una gran ciudad";

b) oraciones de pseudobjeto o cuasisintácticas o modo material de hablar: "Se habló de Babilonia en la conferencia de ayer";

c) oraciones sintácticas o modo formal de hablar: "La palabra 'Babilonia' ocurrió en la conferencia de ayer".

Carnap advierte que muchas de-las marañas en nuestras argumentaciones resultan de usar el modo material de hablar en lugar del modo formal, pues esta confusión comienza por bloquearnos la comprensión de lo que estamos discutiendo: creemos encontrarnos en un debate sobre objetos extralingüísticos como números, cosas o propiedades, cuando en realidad discutimos acerca del lenguaje y sus conexiones, acerca de expresiones numéricas o designaciones de cosas.

Casi diría que, lamentablemente, una reconstrucción formal, lejos de ofrecernos el procedimiento inocente y casi mecánico que muchas veces Carnap busca presentarnos para eliminar los bloqueos de la argumentación, a menudo no puede dejar de constituir una riesgosa interpretación. A este

3 Op. cit., p. 237.

4 Op cit. p. 286. 
respecto, el ejemplo citado de Carnap era tan malo que habló por sí solo: "La palabra 'Babilonia' ocurrió en la conferencia de ayer" en ningún sentido es una reconstrucción formal de "Se habló de Babilonia en la conferencia de ayer". Más todavía, ambos enunciados son por completo independientes: mientras que la palabra "Babilonia" podría ocurrir, y reiteradamente, en una conferencia sobre Carnap, acaso en una sutil conferencia sobre Babilonia no se use nunca el nombre propio "Babilonia".

Estos problemas no sólo recibieron la atención de los "formalistas"; G. Ryle, en "Expresiones sistemáticamente confundentes" se enfrentó a dificultades parecidas, con un diagnóstico similar, aunque con una muy diferente terapia. Para Ryle, la reconstrucción formal en un lenguaje canónico no posee ningún privilegio; de lo que se trata, sobre todo, es de reconducir aquellos lenguajes que por alguna razón confunden a los lenguajes prácticos de la vida cotidiana, como se hizo en (2) con (1). El contraste entre ambas posibilidades de la reconstrucción formal dio lugar a vivas y apasionadas polémicas ("filosofías del lenguaje formal" versus "filosofías del lenguaje ordinario"); unos pocos años de distancia permiten observar ya el mecanismo falaz en que descansaban tales pasiones: la falsa oposición. Según sus intereses y el grado de formalización que requiera la discusión en que se encuentre el intérprete, tanto una formalización lógica - como (5) de (3)-, como una paráfrasis en los lenguajes cotidianos - como (2) de (1)—, pueden resultar útiles para "hablar mejor de lo mismo".

Por otra parte, conviene recordar que una reconstrucción formal puede apoyarse en la forma gramatical superficial, como en alguna medida lo hice cuando propuse (5) para reconstruir (3), pero también se puede no hacerlo. En el caso en que lo hiciéramos, por ejemplo, los adverbios serán pensados como operadores lógicos primitivos que transforman un predicado o una oración en un predicado o en una oración diferentes y, así, habrá que formular tantas reglas lógicas como los operadores primitivos que se introduzcan. No obstante, la reconstrucción formal puede partir también de las estructuras profundas que estudia la' gramática transformacional; en este caso, los adverbios podrían ser tratados como formas superficiales de predicados, representados por sus correspondientes adjetivos y verbos, evitándose de esta manera la introducción de nuevas reglas lógicas.

Regresemos a nuestro inventario de algunas técnicas de reconstruir. A menudo las reconstrucciones formales, en cualquiera de sus modalidades, no son suficientes para volver a poner en marcha un ciclo argumental bloqueado; hay que complementarlas con lo que se puede llamar "reconstrucciones conceptuales": dejamos de hablar con ciertas palabras y comenzamos a hablar sobre ellas; como suele decirse en lógica, dejamos de usar ciertas palabras y comenzamos a mencionarlas (habitualmente, poniendo entre co-

5 Proceedings of the Aristotelian Society, vol. 32 (1931-1932). 
millas esas palabras). En una reconstrucción formal preocupa de manera preponderante la estructura que configuran las llamadas "palabras lógicas" ("no", "y", "si-entonces"...); en una reconstrucción conceptual se atiende ante todo al significado de las palabras no lógicas:

Para llevar a cabo una reconstrucción conceptual del enunciado $E$ se tiene que:

a) dejar de usar $E$;

b) mencionar alguna o algunas de las palabras no lógicas que formaban $E$ y construir enunciados que informen con más claridad (i) lo que se quería decir con $E$ o (ii) lo que se debería querer decir con $E$.

Procuremos formular algún candidato lo más simple posible para ser la reconstrucción conceptual de (3):

(6) Por "saber" se entiende una creencia verdadera y justificada, con frecuencia justificada con argumentos; de ahí que el saber sea inmune a actitudes como ofender o temer, actitudes que se adoptan con respecto a alguna forma de poder; en efecto, en relación con el poder no se puede tener en cuenta otro poder que el poder de los buenos argumentos.

Las reconstrucciones conceptuales suelen despertar más controversia que las formales, hecho que tiende a olvidarse. ¿Por qué?

La reconstrucción conceptual distingue entre el uso y la mención de una o varias palabras; al mencionarse una palabra, esta palabra se convierte en el nombre de sí misma. A veces se confunde, sin embargo, entre un objeto y su nombre y, de esta manera, se olvida que un enunciado debe contener el nombre del objeto y no el objeto mismo. Si el objeto es una ciudad, circunstancias físicas no nos permiten usarlo en lugar de su nombre (no es posible ubicar una ciudad como sujeto de un enunciado que está hecho sólo con palabras); si, en cambio, hablamos acerca de palabras, se comete el error con facilidad. Pero, cuidado, atendamos los siguientes enunciados:

(7) "México" tiene seis letras.

(8) "México" designa una ciudad demasiado grande.

Los enunciados (7) y (8) predican del nombre de un objeto, no del objeto mismo. A la predicación que hacemos en (7), Quine la llama "propiedad morfológica", a la de (8), "propiedad semántica"; 6 esta terminología sugiere, sin embargo, un paralelismo que confunde. El dato que se oscurece, creo, es que en (7) se atribuye una propiedad a una palabra en tanto objeto p. 24.

6 W.V.O. Quine, Mathematical Logic, Harvard University Press, Cambridge, Mass., 1951, 
físico entre los objetos físicos, o si se prefiere, en tanto instanciación física de un objeto sintáctico; en (8), en cambio, se atribuye una propiedad al uso social de una palabra. Nada que le suceda a la ciudad de México oal uso social de la palabra "México" puede modificar la verdad de (7). Pero si, por ejemplo, la ciudad de México dejase de ser una ciudad demasiado grande, (8) sería un enunciado falso.

Quine distingue, pues, claramente entre el objeto y su nombre para confundir mejor, con respecto a las palabras, entre el nombre del objeto y lo que se podría llamar el "nombre del uso" de tal objeto. Tal confusión es quizá explicable si se consideran algunos de sus propósitos teóricos más abarcadores: hay que tener en cuenta lo que Quine llama "ascenso semántico". Esta técnica es otra manera de denominar lo que he llamado "reconstrucción conceptual" y permite, según Quine:

llevar la discusión a un dominio en el cual ambas partes coinciden más fácilmente acerca de objetos (que son palabras) y de los términos principales referentes a ellos. Las palabras o sus inscripciones - a diferencia de los puntos, los metros, las clases y todo lo demás de este tipo- son objetos tangibles. ${ }^{7}$

Nos encontramos en este pasaje con una ansiedad por evitar las perplejidades, los conflictos y los problemas del interpretar, similar a la de Carnap. La afirmación de que "las palabras son objetos tangibles acerca de los cuales se puede producir acuerdo sin dificultad" es verdadera si nos referimos a enunciados de la clase a la que pertenece el enunciado (7), pero falsa con respecto a los enunciados de la clase a la que pertenece el enunciado (8). Lograr acuerdo acerca de que la palabra "saber" posee cinco letras no es una tarea demasiado ardua. Por el contrario, indagar cuál es la definición o caracterización más adecuada de saber probablemente suscitará agitadas disputas, y algo similar ocurre con los conceptos de ofender y temer. De ahí que, como los intérpretes en sus reconstrucciones conceptuales o ascensos semánticos manejan casi exclusivamente enunciados de la clase a la que pertenece el enunciado (8) -enunciados sobre el uso social de las palabras-, una reconstrucción conceptual o ascenso semántico, en lugar de lograr consenso, acaso provoque desacuerdos aún más radicales que los que existían antes de llevar a cabo la reconstrucción. Esto es porque los usos de las palabras son variados y a menudo problemáticos, y no sólo en aquellas palabras que directa o indirectamente se vinculan con fuertes intereses sociales. Lo que es otra manera de expresar: en muchos de los conceptos, en el límite, más o menos indirectamente en todos los conceptos, repercuten algunas de las convulsiones históricas de las "formas de vida", de las culturas, en las cuales se elaboran o se usan tales conceptos, y ningún intérprete

7 W.V.O. Quine, Word and Object, The MIT Press, Cambridge, Mass., 1964, p. 272. 
es por completo inmune a tales convulsiones (diremos más acerca de ello cuando se introduzca el concepto de política conceptual).

Por eso, a menudo importa no tanto repasar uno a uno los conceptos lógicos y no lógicos que constituyen un enunciado, sino, más bien, explorar el papel que desempeña ese enunciado en un debate, esto es, reconstruir el propósito o alguno de los propósitos con que se introduce un enunciado o un argumento. $\mathrm{Al}$ respecto, hablaré de una reconstrucción funcional:

Para llevar a cabo una reconstrucción funcional del enunciado $E$, se tiene que:

a) dejar de usar el enunciado $E$;

b) recoger la función o las funciones que el uso de $E$ (i) querría poseer o (ii) debería querer satisfacer en un debate dado.

A menudo, para realizar una reconstrucción funcional se necesita la referencia específica a una situación de discurso bien concreta; así, imaginemos un intérprete en cierta situación en la que una reconstrucción funcional del enunciado (1) podría ser:

(9) Afirmar que "Segismundo nos dará trabajo pronto", más que entregar una información sobre lo que va a suceder en un futuro próximo, tiene como propósito crear cierta atmósfera de empuje en los participantes de ese grupo teatral para que, precisamente, se haga verdad tal enunciado. Lo que quiere decir este enunciado es, pues: "Hagamos que la representación de La vida es sueño nos permita trabajar pronto".

Otras veces, en cambio, la reconstrucción funcional no necesita vincularse a un discurso específico sino, más bien, a tipos de discursos, tipos incluso muy generales. Por ejemplo, con respecto al enunciado (3), una reconstrucción funcional podría ser:

(10) Sentencias como "el saber no ofende ni teme" suelen usarse para defender socialmente a los diferentes saberes y a instituciones que los producen, como las universidades, de las intromisiones del poder político. A la vez, indirectamente, con esa sentencia se atacan formas de producir creencias o de inducir a la acción no respaldadas en el saber, sino en la ignorancia y su consecuente autoritarismo religioso, político, militar o económico.

Conducir una reconstrucción funcional nos hace topar con más dificultades todavía que las encontradas en relación con las reconstrucciones formales y conceptuales. Si frente a los comentarios sobre los conceptos lógicos y no lógicos que constituyen un enunciado con frecuencia no se puede eliminar la controversia y, en cualquier caso, estamos muy lejos del ideal tanto de Carnap como de Quine de "coincidir fácilmente" (en el "modo formal 
de hablar", "sobre objetos tangibles"), la controversia crecerá aún más, y hasta se multiplicará en direcciones divergentes cuando se busca indagar el por qué o para qué de un enunciado o de un argumento. Sin embargo, presiento que tales controversias, lejos de hablar en contra de la reconstrucción funcional, o por lo demás, de cualquier reconstrucción, vuelven aún más imprescindible la luz interpretativa - poca o mucha- que éstas puedan arrojar.

De todas maneras, no se dispone de ninguna mejor opción en el argumentar —en general: en la comunicación-que el papel del intérprete. $O$ si se prefiere, en principio, no hay ninguna mejor opción que las actitudes que se dejan guiar por lo que podríamos llamar "máxima de las reconstrucciones":

Si en un ciclo argumental, o en general, en cualquier comunicación te encuentras con faltas de comprensión, ante todo intenta reconstruir, de la mejor manera posible, los enunciados de tu adversario.

¿Por qué eso de "en principio" y "no hay ninguna mejor opción que las actitudes que se dejan guiar..."? Por supuesto, en algunos contextos $\mathrm{d} \epsilon$ discusión - por ejemplo, en un acalorado debate, sobre todo de orden práctico - tal vez resulte de la mayor utilidad agarrarse de las imprecisiones o torpezas del otro para hacerlo pedazos, a veces incluso sea productivo forzar sus palabras y hasta malinterpretarlo. Sin embargo, esta manera de comportarse, la "actitud polémica", sólo puede resultar ocasionalmente productiva si es precisamente eso, una excepción. En cambio, creo que como actitud general conduce al desastre teórico y, a la larga, práctico. ¿Por qué?

Supongamos que frente a cualquier desliz $\longrightarrow$ imprecisión, torpeza... de quien ocupa el papel del proponente, el oponente, sin preocuparse por pedir auxilio al interpretar, pasa despiadadamente al ataque, razonando algo así como: "Quien no se sepa expresar con claridad, peor para él; en cuanto a los enunciados que no estén adecuadamente construidos, no puedo perder el tiempo con ellos." El vicio principal de estas razones (de estas agresiones) no es sólo la arrogancia, sino más bien aquello a que conduce este tipo de arrogancia hermenéutica: el monólogo opresivo, o mejor, la opresión del monólogo y sus culturas amuralladas, homogéneas, no menos asfixiantes por muy compartidas que sean. Más todavía, una correcta caracterización de cualquier cultura amurallada debe incluir la condición de consistir en una cultura que elimina, $o$ al menos restringe decisivamente, las tareas del intérprete.

Atendamos una vez más los tipos introducidos de reconstrucción. Observemos que en cada ocasión se vuelve a hablar de dos pasos: en el primero, o paso a), se deja de usar el enunciado en cuestión para atenderlo, y en el segundo, o paso b), se propone la forma lógica o un comentario conceptual o funcional. En cada tipo de reconstrucción, en el paso b), se plantea, sin 
embargo, una alternativa: se alude a (i) "lo que se quería decir" o (ii) "lo que se debería querer decir" con el enunciado que hay que reconstruir, y también a la función que el uso de ese enunciado (i) "querría" o (ii) "debería querer" satisfacer. Por un lado, nos encontramos, pues, con que la reconstrucción busca aclarar —elucidar... - un enunciado o un argumento, reubicándolos en relación con su contexto de producción; por otro lado, la reconstrucción nos conduce a buscar el mejor contenido posible de enunciados o argumentos.

Podemos distinguir ya, entonces, dos direcciones básicas de una reconstrucción. La primera es la reconstrucción genética, "lo que se quería decir", la función que el enunciado "querría satisfacer":

Para llevar a cabo una reconstrucción genética del enunciado $E$, se tiene que:

a) dejar de usar $E$;

b) formular $E$ como un testimonio personal o un documento social.

Por ejemplo, nuestro primer caso de reconstrucción formal, la reconstrucción formulada en (2) del enunciado (1) fue genética: lo que interesaba al intérprete no era examinar qué podría querer decir la oración "Segismundo nos dará trabajo pronto" en varias situaciones diferentes, sino averiguar qué quería decir un hablante en cierta situación específica. El intérprete que formuló la reconstrucción (2) partió, pues, de las presunciones de que el hablante en cuestión, el actor que usaba (1) en un contexto práctico, quería decir algo con sentido, verdadero y con valor para sus oyentes: que no quería poblar el mundo con ficciones, sino que pretendía trasmitir con ellas un mensaje y, a la vez, dar ánimo a sus compañeros. Es esta genuina intención del hablante lo que el intérprete de la reconstrucción (2) buscó recobrar. Si no me equivoco, lo que D. Davidson llama "interpretación radical" es una manera de llevar a cabo reconstrucciones (de todo tipo) en su dirección genética. ${ }^{8}$

En la dirección genética, el reconstruir no se deja guiar por ningún interés prescriptivo; así, por ejemplo, una reconstrucción formal en su dirección genética encontrará en la forma cuantificacional una manera de volver más transparente la gramática del lenguaje "natural", pero el simbolismo no se concibe, como en Carnap, como un hablar mejor de aquello que habla el lenguaje ordinario, sino sólo como un comentario teórico de este lenguaje (comentario que, sin embargo, podrá ayudar a eliminar bloqueos de la argumentación).

8 Cfr. D. Davidson, Inquiries into Truth and Interpretation, Clarendon, Oxford, 1884; al respecto se encuentra también mucho material en Truth and Interpretation: Perspectives on the Philosophy of Donald Davidson, E. Lepore (comp.), Oxford, 1986. 
Por otra parte, en los ejemplos introducidos hasta el momento, al intérprete se le hizo fácil el trabajo en su dirección genética, pero si no se quiere sucumbir en un vértigo simplificador hay que subrayar que a menudo las tareas del intérprete encontrarán grandes obstáculos. Por ejemplo, resistencias en la persona interpretada, en esos casos -que van desde las situaciones educativas hasta la interrogación policial y la psicoterapia- se podría decir que la reconstrucción genética procura "liberar", "sacar a la luz" o incluso "redimir" la intención de quien habla o escribe.

Se podría llamar "reconstrucción proposicional" a la segunda dirección para reconstruir $\mathrm{o}$, si se quiere ser más explícito, "reconstrucción prescriptiva", esto es, reconstruir "lo que se debería querer decir", las funciones que el enunciado o argumento "debería querer satisfacer en un debate":

Para llevar a cabo una reconstrucción prescriptiva del enunciado $E$, se tiene que:

a) dejar de usar $E$;

b) buscar lo que $E$ razonablemente debería querer decir o el propósito que razonablemente $E$ debería querer satisfacer en un debate.

Lo que nuestro hipotético intérprete formuló en (5), (6) y (10) como una reconstrucción formal, conceptual y funcional de (3) fueron reconstrucciones prescriptivas. En (5), (6) y (10) se buscó llevar a cabo una operación de salvamento de lo que (3) debería querer decir, independiente de las intenciones de quien profirió (3) y de la situación específica en la que (3) fue dicha. Se preguntará: pero ise trata de una operación de salvamento de qué y con respecto a quién? De (3), por supuesto, y para nosotros.

Entonces, así como en la reconstrucción genética el intérprete defiende, por ejemplo, la intención de una o varias personas de la telaraña en la que la han atrapado sus palabras, así también en la reconstrucción prescriptiva el intérprete defenderá el sentido, la verdad y el valor de un enunciado en contra de su expresión inepta o incluso encubridora y confundente: en lugar de lo que el enunciado en su desorden no acaba de decir, la reconstrucción prescriptiva busca esclarecer lo que debería razonablemente decir según las consideraciones del intérprete acerca de lo que significa "razonablemente decir" en esa circunstancia. Por ejemplo, cuando un juez "aplica" una ley subdeterminada a un caso concreto, esto es, cuando echa mano al uso determinante del esquema regla-caso, se encuentra realizando una reconstrucción prescriptiva de tal ley. Sin duda, al juez no le interesa una reconstrucción genética en tanto ro le importa qué estaban pensando los legisladores cuando promulgaron tal ley, sino cómo, según los requerimientos de la justicia, hay que entender tal ley en la situación actual.

En este momento de la reflexión hay que tomar dos precauciones. En primer lugar, la manera de expresarme en relación con las reconstrucciones 
genéticas y prescriptivas podría confundir. A menudo hablé de reconstrucciones genéticas y prescriptivas como si se tratase de dos clases más de reconstrucciones, pero no se trata de eso, sino, como lo indica el paso b) en la caracterización de las reconstrucciones formales, conceptuales y funcionales, de dos direcciones que cualquier intérprete tiene a su disposición.

En segundo lugar, ambas direcciones del reconstruir son divergentes en cierto sentido (en lo que implica la forma de su realización y sus resultados), pero también poseen un suelo común. Atiéndase que con respecto a la dirección genética de las reconstrucciones, se señaló que el intérprete buscó "recobrar la genuina intención del hablante" y hasta se indicó que se podrían usar sin hipérbole palabras como "liberar", "sacar a luz" e incluso "redimir" intenciones. A su vez, con respecto a la dirección proposicional de las reconstrucciones se usó la metáfora de "operación de salvamento" -metáfora que sugiere peligrosos naufragios y arriesgadas aventuras- en relación con lo que un enunciado o un argumento pueden querer decir razonablemente - "razonablemente" según el intérprete. En ambas direcciones del reconstruir, los trabajos del intérprete se dejan guiar, pues, por la misma consigna: reconstruir es rescatar.

Sea, entonces, que el intérprete lleve a cabo una reconstrucción formal, conceptual o funcional, genética o prescriptivamente, de un enunciado o de un argumento, lo que el intérprete procura es, en algún sentido, rescatar de manera tranquila o con riesgos ese enunciado o argumento: el intérprete, pues, busca "hablar mejor de lo mismo". Sin embargo, ¿qué significa tal "rescate" y cuáles son sus consecuencias?, ¿qué implica ese "hablar mejor", y en qué sentido se está hablando mejor "de lo mismo"?

Por lo pronto, antes de responder, tengamos en cuenta que muchos no estarán de acuerdo - tal vez no estarán de ninguna manera de acuerdocon esta caracterización de las tareas del intérprete, y enérgicamente repudiarán la consigna "reconstruir es rescatar" y hasta la expresión "hablar mejor de lo mismo". Por ello, paso a examinar un poco las posibilidades de este repudio, que en la tradición se articuló prefiriendo discutir en torno a otra de las palabras de la trama del interpretar: la palabra "análisis".

\section{Dos consignas opuestas: "analizar es conservar", "analizar es eliminar"}

La elección de una palabra a veces es ya una declaración de principios. Sin duda, no fue inocente en la trama de palabras que aluden a las tareas del intérprete elegir la palabra "reconstruir" y no la más tradicional "analizar"; retomo esta última palabra, sin embargo, para no alejarme demasiado de las discusiones de la historia (una forma de la reconstrucción genética). Porque, claramente, si llevamos a cabo una reconstrucción conceptual de operaciones que agrupamos como "interpretar" (en su dirección genética), de inmediato nos topamos con lo que llamaré la "reconstrucción positiva" 
del análisis, cuyo principio es: no hay análisis sin identidad, principio que respalda la consigna: analizar es conservar.

Según tal reconstrucción positiva, el intérprete parte de un enunciado o conjunto de enunciados $A$ que se quiere analizar o analysandum; el resultado de su análisis será ese mismo "objeto" $A$, pero aclarado, precisado, expresado con mayor rigor, el analysans $A^{\prime}$; por supuesto, si se trata del mismo "objeto", digamos, del "mismo pensamiento" en el sentido que Frege da a esta palabra, $A$ es idéntica a $A^{\prime}$ y "analizar es conservar" ese "pensamiento fregeano".

La reconstrucción positiva es la reconstrucción más popular del análisis y domina no sólo la vida cotidiana; matemáticos, físicos, biólogos, lingüistas, sociólogos, teóricos de la ciencia suelen adherirse por igual a ella: así, la operación del análisis se encuentra más cerca del descubrimiento que de la estipulación. El analista, "purificando", descubre o casi; en ningún caso inventa. De esta manera, se propone comúnmente que ciertos aspectos del "objeto" a que nos referimos con ciertas expresiones permanecen ocultos antes del análisis de esas expresiones, y que el análisis precisamente nos los descubre. Por ejemplo, durante mucho tiempo se habló de los números naturales, de los cuerpos que caen y de la burocracia, pero después de los análisis respectivos de Frege, Newton y Weber, quien acepte tales análisis sobre esos "objetos" como análisis correctos, podrá hablar mejor sobre esos mismos "objetos". Por ejemplo, si se acepta el análisis de Frege sobre los números naturales, se lo acepta porque se lo considera adecuado a la práctica con números naturales previa al análisis, esto es, como una reconstrucción verdadera de esa práctica, y no porque Frege haya redefinido convencionalmente, aunque de manera muy útil, tal expresión, y lo mismo con los otros análisis.

No sorprende, pues, que la reconstrucción positiva del análisis haya sido y sea tan popular, ya que es, sin duda, muy atractiva:

a) otorga neutralidad valorativa al analista;

b) fomenta la continuidad histórica; y así,

c) hace posible el desacuerdo racional y, con él, el aprendizaje.

El analista (matemático, físico, sociólogo...) se sitúa "de manera neutral" frente a su "objeto" y, al analizarlo, lo investiga; por eso, los diferentes analistas pueden discutir a través de las épocas sin cambiar de tema: los análisis de Newton "hablan mejor de lo mismo" que los análisis de Ptolomeo; más todavia, si ambos se hubiesen podido encontrar hubieran podido discutir racionalmente como dos colegas que discuten sobre un "mismo" asunto, y en tal discusión, Ptolomeo podría haberse corregido y haber aprendido mucho de los análisis de Newton. De esta manera, podemos pensar la tradición del análisis como un continuo de tareas comunes con desacuerdos 
racionales ante los "mismos" problemas, no como un mero intercambio de actitudes ciegas e intereses inconmensurables.

Quiero detenerme, por eso, aunque brevemente, en un reciente y poderoso defensor de tal concepción. Analizando el concepto de definibilidad (aplicado a la definición de clases de números), Tarski indica:

Nuestro interés se dirige a un término del cual podemos dar una caracterización con un contenido intuitivo más o menos preciso, pero cuya significación no ha sido establecida rigurosamente... Tratamos de construir entonces una definición de este término que, al mismo tiempo que satisface los requisitos del rigor metodológico, expresa de modo adecuado y preciso el significado real del término.9

Este pasaje de Tarski nos ofrece de manera bastante explícita un ejemplo excelente de reconstrucción positiva del análisis: se parte de ciertas caracterizaciones y se busca darles mayor rigor. El analista "saca a la luz" lo que estaba ya ahí, "escondido".

A. Coffa, en una brillante polémica con T. Simpson acerca de la naturaleza del análisis, ${ }^{10}$ resumió de la siguiente manera el proceso de la reconstrucción tarskiana (en la trama de palabras del interpretar, la palabra elegida por Coffa es "elucidación"):

Primer paso: introducción del concepto que hay que elucidar (explicandum), se trata de un concepto relativamente vago;

Segundo paso: exposición de las condiciones que cualquier concepto debe satisfacer si ha de servir como explicatum del explicandum dado, requisitos derivados por medio de un análisis parcial del explicandum;

Tercer paso: formulación del preciso explicatum, un concepto que satisface las condiciones del segundo paso.

Recordemos que Coffa traduce con la palabra "elucidación" la palabra inglesa "explication", introducida por Carnap para identificar su propia concepción sobre la trama del interpretar —de ahí los términos latinos-y sólo usa la palabra "análisis" para el segundo paso.

Regresemos a Tarski. Aunque sin debilitar su fervor por las reconstrucciones positivas del análisis, una página después del último pasaje citado, discutiendo el análisis de los conceptos de superficie y dimensión, Tarski matiza un poco afirmando que:

en geometría el problema era volver precisas las intuiciones parciales adquiridas empíricamente en la vida cotidiana, intuiciones que por su propia natu-

9 A. Tarski, Logic, Semantics and Metamathematics, Oxford University Press, Oxford, 1956, pp. 111-112.

10 En Crítica, Revista Hispanoamericana de Filosofía, México, vol. VII, no. 21, diciembre de 1975. 
raleza son vagas y confusas... Los geómetras se vieron obligados a elegir uno entre varios sentidos incompatibles. ${ }^{11}$

¿Hasta dónde esta "reconstrucción positiva complicada" se distingue de la "reconstrucción positiva simple"? Puesto que los conceptos analizados poseen diversos grados de imprecisión y vaguedad, no es posible postular una identidad estricta entre un analysandum confuso y vago, y un analysans claro y preciso, sino sólo una "identidad parcial" - pero, ¿qué es eso? y, además, ¿qué hacemos con el principio "no hay análisis sin identidad"? Por otra parte, si el análisis se hace eligiendo a cada paso entre varias opciones, no sólo se tambalea la tan - tradicionalmente- loada característica a) del proceso del análisis, la "neutralidad valorativa" del analista. Más todavía, aparece claramente su constante intervención: su eliminar y agregar materiales para que el resultado del análisis resulte satisfactorio.

Casi diría que, lamentablemente, con esta "complicación" no se acaba con las dificultades de la reconstrucción positiva del análisis, por el contrario, éstas apenas despuntaron; entre los múltiples enredos a que se enfrentará quien defienda la reconstrucción positiva me limito a señalar dos. En primer lugar, la reconstrucción positiva parece presuponer alguna variante del platonismo: se presupone que el concepto analizado existía de manera vaga o ambigua antes de analizarse y que, además, se pueden comparar diferentes análisis de un mismo concepto. Por eso, al introducirse la reconstrucción positiva del análisis no resulta casual que se propusiera a los pensamientos fregeanos como candidato a ese mismo objeto que presuponen el analysandum y el analysans.

En segundo lugar, pese a la "complicación" no se aplaca la molestia de la llamada "paradoja del análisis": $s i$ "el enunciado $A=$ el enunciado $B$ " es un análisis correcto del enunciado $A$, y seguimos el principio "no hay análisis sin identidad", entonces ello significa afirmar que "el enunciado $A=$ el enunciado $A$ ". En el caso de que tal identidad se cumpla, el resultado del análisis será trivial, y en el caso contrario, falso. Claro, la "reconstrucción positiva complicada" obliga a introducir el concepto de identidad parcial. Pero ¿se trata de algo inteligible? Y si lo es, ¿en qué sentido evita la paradoja del análisis?

Estas dificultades, si bien no son razones para que rechacemos sin más cualquier reconstrucción positiva del análisis, sí lo son para que comencemos a mirar alrededor buscando una mejor alternativa. Además, si la hay, es tiempo ya de que la investiguemos un poco. Si enfrentamos un enunciado $o$ un conjunto de enunciados $A$ o analysandum confuso y proponemos sustituirlo por un enunciado o un conjunto de enunciados $A^{\prime}$ claro y distinto, ¿por qué no arrumbar definitivamente el principio "no hay análisis sin identidad", lo que de paso nos permite también olvidar la consigna "analizar

11 Op. cit., p. 112. 
es conservar"? A quien suprima tal principio y tal consigna lo consideraré partidario de lo que podría llamarse reconstrucción negativa del análisis. Quine parece ser un buen defensor de esta reconstrucción:

No pretendemos sinonimia. No pretendemos aclarar y explicitar lo que los usuarios de la expresión oscura terían in mente desde un principio. No pretendemos exponer significaciones ocultas, contra lo que sugieren las palabras "análisis" y "explicación". ${ }^{12}$

Como ejemplo característico —o si se prefiere, "paradigmático"— de análisis, Quine ofrece en el parágrafo 53 de Palabra y objeto el análisis de par ordenado llevado a cabo por Wiener y Kuratowski. Estos matemáticos reconstruyen conceptualmente la expresión "el par ordenado $\langle x, y\rangle$ " como sigue:

si $\langle x, y\rangle=\langle z, w\rangle$ entonces $x=z \cdot y=w$.

Luego, al integrar esta formulación en la teoría de conjuntos, Wiener y Kuratowski disponen ya desde este momento de la posibilidad de adscribir valores de verdad a cualquier discurso donde aparezca la expresión " $\langle x, y\rangle$ ". En este análisis del par ordenado, se entiende, pues, la pregunta:

¿qué es un par ordenado?

como equivalente a la pregunta, propia de una reconstrucción conceptual proposicional:

¿qué se debe querer decir cuando se dice "par ordenado"?

En cuanto a que Wiener y Kuratowski no hayan pretendido explicitar lo que tenían en la cabeza los matemáticos cuando, antes de su análisis, usaban la expresión "par ordenado", significa simplemente que Wiener y Kuratowski buscaban una reconstrucción conceptual no genética sino prescriptiva del concepto de par ordenado. Comenta Quine:

En el comienzo fue la noción de par ordenado, defectuosa y enigmática pero útil. Luego los hombres descubrieron que todo lo bueno que se conseguía hablando de pares ordenados $\langle x, y\rangle$ podría lograrse hablando de $\{\{x\},\{y, 1\}\}$, lo que es lo mismo, de $\{\{x\},\{x, y\}\} .{ }^{13}$

Más adelante Quine agrega, no sin cierta polémica puntualizadora y, también, generalizadora:

Analizar (explication) es eliminar. Comenzamos con una expresión o forma de expresión que resulta turbadora o molesta... pero también satisface cier-

13 Op. cit., p. 261. 
tos propósitos que no deben abandonarse. Entonces descubrimos un modo de lograr los mismos propósitos a través de otros medios, utilizando formas de expresión menos turbadoras. ${ }^{14}$

Entre la consigna de la reconstrucción negativa "analizar es eliminar" y lo que después Quine dice que hace siguiendo esa consigna, bordeamos una contradicción (por lo menos, una "contradicción pragmática"). Pero vayamos paso a paso. ¿Qué se propone eliminar Quine? Coffa nos recuerda que dos de las tareas básicas del intérprete consisten, según Quine, en identificar las expresiones oscuras pertenecientes a lenguajes naturales que merecen analizarse (o como dice Coffa "elucidarse") y distinguirlas de aquellas que se deben evitar. Entre estas últimas se encuentran conceptos centrales de la semántica clásica como "significado", "analiticidad", "sinonimia" y "necesidad". Para Quine, las expresiones que ameritan analizarse son, indica Coffa, las que:

aparecen en contextos que, como totalidades, son suficientemente claros y precisos como para ser de utilidad. Elucidarlas será, en esencia, reemplazarlas por otras expresiones que preserven el uso de tales contextos. ${ }^{15}$

La expresión "contextos que, como totalidades, son suficientemente claros y precisos como para ser de utilidad" es un eufemismo importante de Coffa para hablar de las ciencias o, más precisamente, de las ciencias naturales. Califiqué de "importante" tal eufemismo pues, teniéndolo en cuenta, quizá desaparece el aparente acuerdo que se iba esbozando entre Quine y Wittgenstein sobre la trama del interpretar (acuerdo que el propio Quine subraya, no sin cierta ironía). A partir del conocido dictum de Wittgenstein de que la tarea de la filosofía no consiste en resolver problemas sino en disolverlos, y de la conocida imagen de la filosofía como terapia, Quine agrega:

Esta doctrina tiene sus limitaciones pero se ajusta perfectamente a lo que es el análisis (explication). Porque cuando el análisis (explication) prohibe un problema, lo hace mostrando que en un sentido importante el problema es irreal; en el sentido de que procede de usos inútiles. ${ }^{16}$

Entre otras, una diferencia importante entre Wittgenstein y Quine consistirá precisamente en la distinción entre lo que es útil e inútil o, para usar un lenguaje más cercano a Wittgenstein, entre lo que es valioso y aquello que no lo es (distinción que Wittgenstein, a diferencia de Quine, no la

14 Ibid.

15 Loc. cit., p. 44.

16 Op. cit., p. 260. 
volverá parasitaria de esas "totalidades claras, precisas y útiles" que son las ciencias naturales).

Pero volvamos a examinar la consigna de la reconstrucción negativa "analizar es eliminar". En realidad, las consignas se malentienden si olvidamos su dimensión polémica. Quine con la consigna "analizar es eliminar", más que descubrirnos su comprensión del análisis en tanto reconstrucción negativa, nos hace saber que está muy impresionado con la molesta paradoja del análisis que el principio "no hay análisis sin identidad" parece provocar de manera inevitable. Sin embargo, en el comentario de Quine acerca de lo que se hace efectivamente cuando se analiza, se vuelven a poner las cosas en su lugar: analizar es eliminar confusiones y preservar viejos propósitos. Quitando el énfasis retórico de sus consignas, las diferencias entre Tarski y Quine parecen evaporarse lentamente: analizar es reconstruir si reconstruir es rescatar. ¿Es verdad que podemos concluir ya tan amistosamente? Recordemos que Simpson, en la ya aludida polémica con Coffa, subraya, creo que con razón:

Está claro, sin embargo, que para Quine la elucidación es tanto eliminación como preservación, al menos en la medida en que admite contextos privilegiados cuya validez "merece salvarse". ${ }^{17}$

¿Hemos perdido el tiempo, entonces, en una de las tantas polémicas que al final se descubren como confusiones verbales respaldadas en un acuerdo tácito? No necesariamente, pues hay matices diferentes y algo más.

En primer lugar, hay análisis que responden a lo que exigen de ellos sus reconstrucciones positivas simples o "análisis simples": si no entiendo la palabra "soltero" y se me informa "no casado", o si tengo dudas con la palabra "triángulo" y me las despejan, indicándome "figura geométrica de tres lados", esto es, cuando una definición en sentido estricto es posible, estamos, creo, ante esos análisis, y, por lo tanto, ante un análisis a partir de algo así como sinonimia.

En segundo lugar, quienes como, por ejemplo, Tarski y Coffa defienden la reconstrucción positiva complicada del análisis, quienes defienden el "análisis complicado", o como prefiero hablar, quienes defienden la posibilidad de reconstrucciones racionales, tienen razón en insistir que hay tales clases de análisis o reconstrucciones, incluso independientes de cualquier contexto científico, y que tales interpretaciones a veces tratan, además, algunos de los conceptos centrales de cualquier saber e incluso de cualquier vida: por ejemplo, conceptos como los de verdad, átomo, razón, ciencia, oxígeno, virtud, violencia, argumento, capacidad de juicio... Mi conjetura es, pues, que cuando yo protesto ante un ignorante en geografía "es verdad que Buenos Aires es la capital de Argentina", el concepto de verdad que uso es la

17 Loc. cit., p. 78. 
misma verdad que procuran analizar o, más bien, reconstruir Aristóteles y Tarski: "decir de lo que es, que es, y de lo que no es, que no es". La dificultad -y éste es, sospecho, el centro confuso de todas estas polémicas-radica en elaborar esta "mismidad".

Quizá la tradición ha ido a veces por el mal camino al obsesionarse procurando elaborar esta dificultad central para cualquier interpretar, concentrándose en todos los casos en la mismidad de "pensamientos fregeanos", y en el sentido más platónico de esta expresión. Tarski, una vez más, es claro en ello:

La definición deseada no trata de especificar el significado de una palabra conocida empleada para denotar una noción nueva. Por el contrario, trata de captar el significado real de la vieja noción. ${ }^{18}$

Sin embargo, si el análisis complicado o reconstrucción tuviera que tratar de "captar el significado real", preciso, a partir de un significado confuso, esto es, si en la consigna "analizar es conservar" lo que se tiene que conservar debe conservarse en el nivel del sentido pensado como "pensamiento fregeano", creo que el principio "no hay análisis sin identidad" es inevitable y, con él, también es inevitable la paradoja del análisis. Pero ¿en qué otro nivel podría conservarse la identidad del objeto reconstruido si no se la conserva en el nivel del sentido y, a la vez, ay, se quiere defender alguna reconstrucción positiva del análisis?

Por lo pronto, dejemos esta pregunta en suspenso, o más bien, por mor del argumento, supongamos que ya tenemos una respuesta a esa pregunta y, no habiendo ya tropiezos con la reconstrucción positiva del análisis complicado, regresamos, otra vez, a Quine. La respuesta de Quine a la primera parte de nuestra terca pregunta acerca de en qué otro nivel podría conservarse la identidad del objeto analizado si no se la conserva en el nivel del sentido, aunque no es muy precisa, es muy sugerente e incluso, diría, muy importante: la identidad se conserva en el nivel de los propósitos, en el nivel de la utilidad téorica o práctica. Sin embargo, de esta manera no se analiza o reconstruye un concepto, sino que se lo reduce a otro o se lo elimina; en cualquier caso, se lo reemplaza. Los debates cotidianos y la historia de las diversas ciencias se encuentran llenos de estos reemplazos conceptuales que, a menudo, les han abierto caminos insospechados.

Las tareas del intérprete, las tareas para quitar los bloqueos de un ciclo argumental, se han, entonces, multiplicado. Doy una lista provisoria de algunas de esas tareas. El intérprete puede:

A) ofrecer un análisis proponiendo condiciones necesarias y suficientes: "reconstrucciones positivas simples del análisis" o "análisis simple" o "análisis por sinonimia" o "análisis" en sentido estricto, como cuando se analiza lo

18 Op. cit., p. 53. 
que se podrían llamar "conceptos cerrados", como "soltero" en tanto "hombre no casado", o "cubo" en tanto "sólido cerrado con cuatro lados";

B) reconstruir objetos y prácticas en uso: "reconstrucciones positivas complicadas del análisis" o "análisis complicado" o "análisis sin sinonimia" o "reconstrucciones" propiamente dichas, como cuando se reconstruyen "conceptos abiertos": verdad, átomo, ciencia, justicia;

C) introducir reemplazos, reducciones o eliminaciones: "reconstrucciones puramente negativas del análisis", si se reduce el agua a su fórmula química de $\mathrm{H}_{2} \mathrm{O}$, o como cuando el pensamiento de la Ilustración eliminó el concepto de bruja o Lavoisier el de flogisto.

Por lo pronto, las dificultades más urgentes de resolver se concentran en B), en la "reconstrucción complicada del análisis"; quiero decir, tenemos que examinar en qué descansa la posibilidad de las reconstrucciones propiamente dichas, la posibilidad de las reconstrucciones capaces de "hablar mejor de lo mismo", sin sinonimias de sentido.

\section{Teorías de la referencia directa y políticas conceptuales}

Retomemos, pues, la pregunta: ¿en qué otro nivel podría conservarse la identidad del "objeto" reconstruido, del "objeto" antes y después de la reconstrucción, si no se la conserva en el nivel del sentido? La respuesta más inmediata y más simple es probable que sea: en el nivel de la referencia. No obstante, esta respuesta está prohibida, resulta incluso ininteligible si se acepta un principio que, a primera vista al menos, ha resultado históricamente y continúa resultando altamente plausible: el principio de la determinación de la referencia por parte del sentido. ${ }^{19}$

Por ejemplo, cuando Frege, en "Sobre el sentido y la referencia" introduce precisamente la distinción entre sentido y referencia, caracteriza los sentidos como "modos de presentación" de la referencia, modos de presentación que conforman la ruta obligada hacia el referente. La referencia de la "estrella vespertina" es la misma que la de la expresión "estrella matutina", no así el sentido de ambas expresiones. Sin embargo, no podemos acceder a esa referencia más que por medio del inevitable rodeo de sus diversos "modos de presentación": los sentidos determinan por completo cuál es la referencia en cuestión y, por eso, la referencia será, entonces y en todos los casos, necesariamente indirecta. El principio de la determinación de la referencia por parte del sentido puede expresarse también en tanto principio de la referencia como necesariamente indirecta.

19 C. Lafont, en su excelente libro La razón como lenguaje, ha estudiado los efectos de este principio que ella llama "la tesis de la preeminencia del significado sobre la referencia", en la tradición alemana de filosofía del lenguaje (de Hamann a Habermas) y los ha criticado, como yo haré también en lo que sigue, a partir de la teoría de la referencia directa. 
Sin embargo, ino sería posible indicar, por lo menos, algunos contraejemplos de este principio? Elaboro uno en torno a un contraejemplo conocido propuesto por K. Donnellan. ${ }^{20}$ Imaginemos que se encuentra el cadáver de Smith horriblemente mutilado, y un vecino, sin más saber que el que le ofrece su percepción inmediata, profiere la oración:

(1) El asesino de Smith está loco.

En esta situación (1) se usa con el sentido de:

(2) Cualquiera que haya mutilado de tal manera el cadáver de Smith tiene que estar loco.

Ahora bien, supongamos que la policía ya encontró al sospechoso del asesinato de Smith y un médico después de examinarlo profiere (1); en esta segunda situación (1) posee el sentido de:

(3) La persona que acabo de examinar y que está inculpada con el asesinato de Smith es un demente.

Sin duda, el uso de (1) como (2) y de (1) como (3) es diferente. Donnellan llama al uso (2) de (1) "uso atributivo", y al uso (3) de (1), "uso referencial". Si hay tal cosa como un uso referencial, no atributivo o no puramente atributivo del lenguaje, podría haber, pues, una referencia directa al mundo por parte de nuestras descripciones definidas, incluso cuando éstas fuesen falsas.

¿Cómo es esto? Supongamos que luego de consultar con el médico, la policía hace revisar al sospechoso de asesinar a Smith por un psicólogo y éste informa:

(4) El sospechoso del asesinato de Smith no está loco, más todavia, es una persona muy razonable que dudo que haya asesinado a alguien.

En efecto, poco después se descubre que Smith no fue asesinado sino destrozado por un tren. En este caso, al afirmar (1) con el sentido de (2), el vecino no se habría referido a nadie: el vecino, al haber afirmado (2), sencillamente estaría equivocado por completo porque la descripción definida usada por él era falsa. En cambio, el médico no se habría equivocado totalmente al afirmar (1) con el sentido de (3), pues sí se habría referido a alguien, en tanto que sus oyentes han entendido a quién quería referirse con (3). Por eso, el psicólogo lo podría corregir: "ese pobre hombre no estaba loco ni había asesinado a nadie".

El uso referencial de las descripciones definidas es, entonces, un claro contraejemplo del principio de la determinación de la referencia por parte del

20 "Reference and Definite Descriptions", en S.P. Schwartz (comp.), Naming, Necessity and Natural Kinds, Nueva York, 1977. 
sentido o principio de la referencia como necesariamente indirecta, porque en tal uso el sentido, la descripción definida empleada, no es la ruta o rodeo obligado al referente, sino sólo un "instrumento" entre otros para referirnos a él, que, en tanto mero "instrumento", si se lo considera inadecuado, puede ser sustituido. De esta manera se puede referir directamente, usando cualquier descripción, nombre o gesto que se considere útil, independiente de la verdad acerca de tal descripción, nombre o gesto. Así, como indica Donnellan, resulta:

un sentido en el que tenemos que ver con la cosa misma y no con la cosa bajo cierta descripcion. ${ }^{21}$

Sin embargo, esta afirmación de Donnellan y, en general, su distinción entre usos atributivos y referenciales confunden con facilidad.

En primer lugar, la rotunda afirmación citada puede malentenderse como si se propusiera una teoría de la "referencia puramente inmediata": la posibilidad de una aprehensión descontextualizada de los objetos, de la "cosa misma", sin la mediación directa o indirecta del lenguaje. Sin duda, no es posible ningún referir puramente inmediato, ningún designar sin el marco de un lenguaje con descripciones definidas, nombres..., y sus consecuentes atribuciones de propiedades al referente, $y$ todo ello en medio de un contexto práctico. Como hemos aprendido, hasta la definición ostensiva se encuentra directa $o$ indirectamente enmarcada por palabras y contextos de referir y, por ello, tiene sentido sólo en cierto contexto articulado por un lenguaje, explícito o implícito. Sin embargo, defender la posibilidad de la referencia directa no es proponer una referencia inmediata: postular la existencia de una referencia directa "a la cosa misma" y no a la "cosa bajo cierta descripción" no pretende, por ejemplo, prescindir de los sentidos de las descripciones definidas, sino sólo negar que el éxito en el designar dependa necesariamente de la verdad de las descripciones usadas. Se ha visto que esto no es así en el caso de nuestro médico, a quien el psicólogo le puede corregir todas las descripciones que usa - la persona por él examinada no asesinó a nadie ni estaba loco- sin que por ello él deje de referir. Entonces, pese a que se contradecían en todos los usos atributivos de todas sus descripciones definidas, el médico y el psicólogo "hablaban de lo mismo"; la única diferencia entre ambos era, pues, que el psicólogo "hablaba mejor" pero... "hablaba mejor de lo mismo". Estas últimas comprobaciones son decisivas: sin la posibilidad de una referencia directa, desaparece la posibilidad de corregir y hasta de autocorregirse y, por lo tanto, la posibilidad de "hablar mejor de lo mismo". Así, un intérprete, frente a bloqueos de la comunicación por faltas de comprensión, no podría apelar nunca a una reconstrucción.

21 Loc. cit., p. 65. 
En segundo lugar, si se aceptan las últimas consideraciones, por lo menos para una clase de análisis, para la clase B), para las reconstrucciones de conceptos abiertos, ya se dispondría de una "solución", o quizá mejor "disolución", de la "paradoja del análisis": con respecto a una reconstrucción no hay tal paradoja pues "la mismidad conservada", la "identidad", se encuentra en el nivel de la referencia, no en el de los sentidos.

Por otra parte, hay que cuidar de no confundir la distinción entre usos atributivos y usos referenciales con la distinción entre sentidos del hablante y sentidos de la lengua. Creo que las dos distinciones parten de que es posible distinguir entre lo que una oración dice y lo que un hablante puede "hacer" con tal oración; pero, si no me equivoco, ambas distinciones poseen funciones relativamente independientes y, si se las funde, se pierde la utilidad de ambas. La segunda distinción, la distinción entre sentidos del hablante y del habla nos recuerda que un hablante en la práctica puede darse a entender usando de manera desviada y hasta completamente extravagante los sentidos "normales" de las palabras, los sentidos de la lengua. La ironía, el sarcasmo, el albur y otras figuras del lenguaje, y hasta nuestras frecuentes equivocaciones con el sentido "normal" de las palabras, que, sin embargo, no bloquean la comunicación, viven de esa posibilidad. Por ejemplo, si yo frente a un miserable trabajo sobre la ética kantiana, que ubica tal ética como un excelente ejemplo de utilitarismo, exclamo "iqué maravilla!", seguramente se entenderá lo que he querido decir.

Tal vez se podría indicar una diferencia entre estas dos distinciones como sigue:

a) la distinción entre usos atributivos y referenciales subraya el hecho de que se puede referir satisfactoriamente, entre otros recursos del lenguaje, con descripciones definidas falsas, con "sentidos equivocados";

b) la distinción entre sentidos de la lengua y sentidos del hablante, en cambio, apunta, ante todo, al hecho de que se puede sustituir un sentido por otro (las figuras de la retórica), sin que por ello falle la comunicación.

La primera distinción, para explicar por qué ciertos errores en el nivel de las descripciones definidas, del "sentido", no arrruinan la comunicación, apela a la práctica y a los referentes extralingüísticos de nuestras palabras; en cambio, la segunda distinción, para explicar hechos en muchos sentidos similares, apela a la práctica y a la "normalidad" del lenguaje, a ese constructo normativo que denominamos "lengua", constructo presupuesto por los hablantes y que recogen y afianzan los diccionarios.

Si no me equivoco, ambas distinciones son contraejemplos del principio de la determinación de la referencia por parte del sentido o principio de la referencia como necesariamente indirecta, pues con ambas distinciones se nos recuerda que los sentidos, que los sentidos de la lengua o sentidos "normales", no son la ruta obligada hacia el referente, sino sólo sus instrumentos, 
pero se trata de contraejemplos diferentes y en este debate sólo interesa la primera clase de contraejemplos.

Vayamos a un ejemplo más enredado, más importante también, que el asesino de Smith: la reconstrucción del concepto de ciencia. Dos reconstrucciones del concepto de ciencia, con frecuencia, se consideran como las "reconstrucciones clásicas": las propuestas por el empirismo lógico, entre otros por R. Carnap y C.G. Hempel, y aquellas defendidas por el llamado "racionalismo crítico" de K. Popper. Para los empiristas lógicos, las instancias del conocimiento científico se configuran con juicios analíticos (definiciones explícitas y de uso) y juicios sintéticos ("relaciones fundamentales" y "elementos fundamentales" que forman parte de esas relaciones); la estructura del conocimiento científico, a partir de las "bases" empíricamente dadas, se construye con medios lógicos siendo, así, deducción y verificabilidad sus dos operaciones fundamentales. En cambio, para Popper no importa tanto la estructura del saber como su crecimiento, por eso, su punto de partida no es ningún enunciado lógico ni ninguna evidencia empírica, sino una hipótesis precisa y consistente que debe proponerse a un experimento crucial, en el que se decidirá si la hipótesis sigue en pie o ha sido rechazada: para el racionalismo crítico, entonces, un enunciado es científico si posee explícitamente falsificadores potenciales, dados por enunciados básicos cuyos valores veritativos se decidirán en un experimento crucial.

¿Hay desacuerdo entre Hempel y Carnap por un lado y Popper por el otro? La pregunta tal vez sorprenda, incluso parezca extravagante: por supuesto que lo hay. La pregunta, sin embargo, resulta perfectamente correcta si invocamos el principio de la determinación de la referencia por parte del sentido o principio de la referencia como necesariamente indirecta. Por ejemplo, si el criterio de verificabilidad de los empiristas lógicos y el criterio de falsación del racionalista crítico fuesen condiciones necesarias y suficientes de cada concepto de ciencia propuesto, en ese caso, empiristas lógicos y racionalistas críticos no estarían "hablando de lo mismo", sino de asuntos completamente diferentes definidos de manera exclusiva por sus respectivos criterios. Precisamente, la sospecha de que ésta ha sido a veces la intención, esto es, de que se ha pretendido usar el concepto de ciencia como sinónimo de las descripciones propuestas y no referencialmente, de que se están ofreciendo, pues, condiciones necesarias y suficientes para "construir" el concepto de ciencia y no propuestas aproximadas para "re-construir" instituciones ya en funcionamiento y, en gran medida al menos, independientes de cualquier metateorización, ha sido una crítica reiterada y, sin duda, poderosa, en contra de esas "reconstrucciones clásicas". Más todavía, a partir de las llamadas "reconstrucciones históricas" de la ciencia, llevadas a cabo por pensadores como T. Kuhn, P.K. Feyerabend y tantos otros, suelen descalificarse las propuestas "clásicas" - iesos usos "puramente atributivos" del concepto de ciencia? - como "utopías lógico-metodológicas". Pues suponer 
que el uso de la descripciones definidas contenidas en las "reconstrucciones clásicas" es puramente atributivo implica la incorregibilidad de tales descripciones: si defino la palabra "ciencia", por ejemplo, como "conjunto de enunciados tales que cada enunciado posee necesariamente falsificadores potenciales", no podré sospechar después que, tal vez, en eso que llamamos "ciencias" existen otros tipos de enunciados, y hasta otro tipo de configuraciones y mucho menos, luego, efectivamente descubrirlas.

Supongamos que éste fuera el caso; y supongamos que desde el horizonte abierto por las "reconstrucciones históricas" se propone que la expresión "aprender ciencia". significa introducirse en un contexto que posee las siguientes instancias:

(a) Legitimadores de la institución (valoraciones de la ciencia en cierta sociedad);

(b) tradiciones de racionalidad teórica (tradiciones de construcción de teorías, de discusión...);

(c) tradiciones de racionalidad práctica (tradiciones de experimentación, de aplicaciones técnicas...);

(d) propósitos internos en tanto criterios de evaluación aceptados por la comunidad científica pertinente.

En esta nueva reconstrucción conceptual prescriptiva -teniendo en cuenta los aportes de la historia y de la sociología - se nos ofrece una caracterización y, en muchos sentidos, una caracterización sólo aproximativa y suficientemente subdeterminada para que se le puedan agregar o rectificar atributos, no una definción cerrada del concepto de ciencia. ¿Se puede entender ello como un ataque a tales reconstrucciones? Si por defirición se pide que la reconstrucción establezca de manera definitiva - ¿convencionalmente? - un sentido de ciencia y que, a partir de esa definción, inmune a la revisión, se deduzcan todas las consecuencias que se siguen de ello, descalificando de manera mecánica como "no ciencia" todo lo que no se deje subsumir bajo dicho concepto, este ataque estaría pidiéndonos lo que seguramente ni siquiera las matemáticas pueden darnos. Pues también el trabajo matemático admite "hablar mejor de lo mismo": nuevas teorías que tratan mejor viejos conceptos.

Tal vez inquiete este apresurado diagnóstico de algunos debates en la teoría de la ciencia reciente, pues en él se reconstruye un grupo de contrincantes como si propusieran utopias, sin buscarlo. Sin embargo, quizá esta sensación de insensatez se disipe si llevamos a cabo reconstrucciones funcionales en la dirección genética de tales propuestas. Quien apenas las esboce de inmediato percibirá que en las "reconstrucciones clásicas" se buscaba un criterio de demarcación preciso, fijo y general (de ahí la preocupación casi obsesiva con el criterio de verificabilidad en Carnap, y con el criterio de 
falsación en Popper), capaz de proteger a las ciencias de sus enemigos, en el caso del empirismo lógico, la metafísica; en el caso del racionalismo crítico, la pseudociencia, por ejemplo, la astrología y la alquimia, pero sobre todo, las pseudociencias, según Popper, como el marxismo y el psicoanálisis, a las que es necesario "desenmascarar" despiadadamente porque representan un genuino y actual peligro. Esta ansiedad del combate con los enemigos de la ciencia o, más abarcadoramente, de la razón, desaparece por completo, o casi por completo, en las "reconstrucciones históricas", más preocupadas por el trabajo de detalle y por la fidelidad empírica y hasta sociológica, incluyendo los cambios y transformaciones del concepto de ciencia a través de las vicisitudes de la historia y de las sociedades, que por teorías prescriptivas generales:

No obstante, cuiłado: sería un grave error, creo, pensar que esas diferentes reconstrucciones por ser guiadas, en parte al menos, por diferentes propósitos "no hablan de lo mismo". Claro que en un alto grado "hablan de lo mismo", por eso sus proponentes han podido discutir y cómo. La reconstrucción conceptual de dirección genética nos ayuda, entonces, a entender en alguna medida -que seguramente exageré- la diferencia entre ambos grupos de reconstrucciones, pero en ningún caso elimina la pregunta: ¿cuál de estas reconstrucciones "habla mejor de la ciencia que las otras"? O con más cautela: ¿cuáles son las verdades, los materiales, que merecen rescatarse de estas reconstrucciones y qué errores e incluso fetiches hay que desechar?

Lo que este ejemplo, espero, ayuda a comprender es que si los concf ptos de ciencia que manejan las diferentes teorías de la ciencia no fuesen u: ædos también referencialmente, y no sólo de manera atributiva, frente a lis diversas descripciones definidas que nos han dado Carnap, Hempel, Popper, Kuhn, Feyerabend y tantos otros, no estaríamos en una situación similar a la que nos encontrábamos en relación con la discusión del médico y el psicólogo con respecto al sospechoso de haber asesinado a Smith. Pero si éste fuera el caso, esto es, si las metateorías de la ciencia fuesen entendidas exclusivamente de manera atributiva y, por lo tanto, no como propuestas por defender y atacar en torno a realidades, en gran parte al menos, independientes de las decisiones de la metateoria, la discusión racional entre los representantes de tales propuestas sería imposible: la mera diferencia obligaría a concluir que tales metateorías no hablan, por definición, "de lo mismo".

En este sentido, la tan festejada tesis de la inconmensurabilidad de las teorías es con frecuencia una de las tantas consecuencias de reducir el lenguaje a su uso atributivo, olvidando que el funcionamiento de cualquier lenguaje natural dispone también de usos referenciales. Esta inconmensurabilidad se ha planteado tanto en el nivel de ejemplos como el discutido, como en el interior mismo de las diversas disciplinas cientificas. En ambos 
casos la inconmensurabilidad es con frecuencia una ilusión del intérprete. Por ejemplo, aunque muchos términos de las ciencias naturales son introducidos en una teoría con una definición explícita, esta definición no es inmune a la revisión como debiera serlo si el término fuese mero sinónimo del definiens. $H$. Putnam recuerda que en la física newtoniana el término "momentum" era definido como "masa por velocidad", pero con la aceptación de la teoría especial de la relatividad surgieron dificultades; Einstein no rechazó la idea de que los objetos tienen momentum pero demostró que el principio de relatividad especial se viola si el momentum fuera exactamente igual a masa por velocidad. Continúo citando a Putnam, largamente:

¿Qué hacer? Einstein estudió el caso "bolas de billar" (partículas en colisión elástica). Dado que la física newtoniana "funciona", el moinentum de estas partículas debe estar dado por la fórmula "masa por velocidad" casi exactamente, al menos cuando las velocidades son no relativistas (esto es, velocidades pequeñas comparadas con $c$, la velocidad de la luz). ¿Puede haber una cantidad 1) que se conserve en colisiones elásticas; 2) que se acerquie cada vez más a "masa por velocidad" a medida que la velocidad se hace pequeña, y 3) cuya dirección sea la dirección del movimiento de la partícula? Einstein demostró que esa cantidad existe y llegó a la conclusión de que dicha cantidad es el momentum mismo. Se revisó el enunciado "el momentum es exactamente igual a masa por velocidad". iPero esto originariamente era una definición! Y fue razonable revisarlo, pues ¿por qué habría de ser más lícito defender el enunciado "el momentum es masa por velocidad" que defender el enunciado "el momentum se conserva", cuando se descubre un conflicto?

Un filósofo tradicional respondería: "porque 'momentum es masa por velocidad' expresa el significado de la palabra 'momentum'. No se puede revisar una verdad analítica". Pero este filósofo está imponiendo un conjunto de categorias -las ideas de definiciones definitivas y de verdad analítica- que no tienen validez en la práctica científica concreta [...]

Otra respuesta tradicional es: "Bien, los científicos decidieron cambiar el significado de 'momentum'". Si esto da cuenta del cambio de valor de verdad que los científicos asignan al enunciado "el momentum es masa por velocidad" luego de adopar la teoría de la relatividad, se sigue, entonces que ahora estamos hablando de una magnitud diferente. Pero, seguimos hablando del famoso momentum -la magnitud que se conserva en colisiones elásticas. A esta magnitud física se refirió siempre "momentum" si se refería a algo. ${ }^{22}$

Si le creemos a Putnam, entonces los físicos, antes y después de la teoría de la relatividad especial, "hablaban de lo mismo" cuando usaban la palabra "momentum", sólo que después de Einstein podían "hablar mejor de lo mismo".

22 Representation and Reality, MIT Press, Cambridge, Mass., 1988 (trad. castellana de G. Ventureira, Barcelona, Gedisa, pp. 33-35). 
Introduje la ilustración de Putnam en contra de los frecuentes abusos inconmensurabilistas. Sin embargo, y para no caer en vértigos simplificadores de dirección opuesta, hay que subrayar que los análisis del tipo $\mathrm{C}$ ) no son raros, que a menudo también reconstruir es eliminar; por ejemplo, con frecuencia se abandonan teorías en torno a conceptos como el de flogisto, en tanto teorías puramente atributivas, sin ningún referente real.

De esta manera, en la mayoría de las argumentaciones, incluyendo los debates científicos, se habla de lo mismo y de lo otro. Esto es, todo ciclo argumental se constituye con continuidades y rupturas, y es también, si no me equivoco, parte de las tareas del intérprete reconstruir de qué clase de continuidades se trata, de qué clase de rupturas y cuán importantes son unas y otras. Sin embargo, ¿cómo es esto? Supongamos que Lavoisier hubiese retenido la palabra "flogisto" y se hubiese limitado a señalar que Priestley sólo estaba equivocado en muchas de las propiedades que se le atribuían al flogisto; en ese caso, lo que nosotros llamamos "oxígeno" se llamaría "flogisto". La pregunta general es, entonces: ¿cuándo, pese a las muchas revisiones en el nivel del sentido, es razonable en nuestras reconstrucciones retener la cadena causal que fijó "originariamente" una referencia, como en el caso de momentum, según Putnam, o para poner un ejemplo similar, como en el caso de átomo, y cuándo es razonable romper esa cadena como lo hizo Lavoisier con respecto al concepto de flogisto?

Tiendo a pensar que en relación con la última pregunta no hay ninguna respuesta precisa, fija y general; más bien, las decisiones se toman según la "política conceptual" que se considera más conveniente. Con respecto a la última afirmación de inmediato se objetará: pero cacaso de esta manera no nos está proponiendo Ud. que las decisiones acerca de lo que hay, que las decisiones ontológicas son arbitrarias? De ningún modo. Como en cualquier política, también en la política conceptual se sopesan hechos y propósitos, descripciones y normas, y según ellos, algunas políticas conceptuales serán buenas y otras no lo serán. Como ya se recordó, la llustración pensó que la política conceptual más adecuada con respecto al concepto de bruja eran las reconstrucciones negativas del tipo $\mathrm{C}$ ), esto es, se trataba de luchar con todos los recursos disponibles por eliminar tal concepto, negando que hubiese mujeres con propiedades tales como las que les atribuía la Inquisición para quemarlas; en cambio, en relación con conceptos como momentum o átomo, los físicos prefirieron reconstrucciones del tipo B), y aunque en ambos casos ésas hayan sido las políticas conceptuales más razonables, no carecería de sentido, digamos, querer discutirlas. Al respecto, tal vez se pueda recuperar algo de las teorías tradicionales, "descriptivistas", de la referencia: si bien las descripciones definidas en ningún caso fijan la referencia, de modo inevitable conforman buenas razones que hay que tener en cuenta en la política conceptual que examina, por ejemplo, si lo más razonable es romper o continuar con la cadena causal de cierta referencia, digamos, si lo 
más razonable resulta proseguir reconstruyendo cierto concepto y "hablar mejor de lo mismo", o eliminarlo y, de esta manera, "cambiar de tema".

\section{Dos dudas}

Entre las muchas interrogantes que todavía habría que plantear en torno a las posibilidades de "hablar mejor de lo mismo", me limito a discutir las dos siguientes: incluso aceptando alguna teoría causal de la referencia, la cadena causal, en realidad ¿qué se conserva en una reconstrucción? Por otra parte, teniendo en cuenta la importancia y hasta ubicuidad de la trama del interpretar, ¿hay que agregar, entonces, a los tres papeles básicos de cualquier argumentación, el del proponente, el del oponente y el del juez, un cuarto papel, el del intérprete?

Empiezo discutiendo la primera duda; creo que los conceptos abiertos que conforman el "objeto" de las reconstrucciones pueden ser de diferentes clases. Es posible que la reconstrucción haga referencia directa a objetos propiamente dichos, como un átomo o un ente de ficción, o a sucesos, como una conmoción; también la reconstrucción puede hacer referencia directa a actividades e instituciones, como es el caso de la ciencia. Los ejemplos más complicados son, creo, los conceptos abstractos, como verdad o razón, pues ¿a qué se refieren las reconstrucciones de tales conceptos? Mi conjetura es que, con respecto a ellas podemos tener en general la siguiente alternativa:

a) en muchos de estos casos "lo mismo" que permanece en la reconstrucción son ciertos tipos de acciones y sus propósitos: por ejemplo, con la reconstrucción del concepto de verdad nos referiremos a actividades como la de asentir frente a la verdad o a la de decir la verdad (la verdad sería la causa de que asintiéramos o de que dijéramos la verdad), y con la reconstrucción del concepto de razón a la actividad de creer y actuar razonablemente; 0

b) en estos casos nos referiremos directamente a una propiedad, la verdad, la razón, propiedad que ha sido reconstruida de diferentes maneras (en un sentido análogo a que un objeto se puede reconstruir de diferentes maneras).

Por lo demás, tal vez no me haya alejado tanto de Quine como parece: Quine propone que con frecuencia el análisis debe eliminar sentidos y retener propósitos; en muchos casos, sobre todo cuando la reconstrucción aluda a acciones, probablemente esto es lo que se hará.

Vayamos a la segunda duda. Incluso para quien considere que puede haber análisis propiamente dicho de conceptos cerrados, teniendo en cuenta que la mayoría de los conceptos son abiertos, la distinción entre las tareas "auxiliares" del intérprete por un lado, y las del proponente y oponente, 
por otro, muy pronto se nos convierte en una idealización: una idealización útil para enfocar nuestra atención en ciertas tareas, pero nada más. Por eso, en el caso de las reconstrucciones es, creo, imposible decidir cuándo termina la reconstrucción del concepto y cuándo empiezan las teorías sobre el objeto en cuestión (recuérdese nuestro ejemplo del concepto de ciencia), en un sentido similar en que con respecto a cualquier concepto abierto es imposible decidir cuándo acaba la información del diccionario y cuándo empieza la información de la enciclopedia. Por eso también, de hecho, y puesto que "reconstruir es rescatar" el papel del "intérprete", al auxiliarnos, necesariamente prolonga $o$ al proponente $o$ al oponente, y así, la trama del interpretar se descubre como otra de las tantas posibilidades del proponente o del oponente. 